\title{
Challenges and Benefits of Inclusive Education
}

\author{
Dr.R. Sree Priya
}

\begin{abstract}
In India all professionals have started to strongly support the philosophy of Inclusive education, to promote the concept of full Inclusion. Inclusion serves as a means to achieve the goal of universal education and to fulfil the provisions of RTE Act, 2009 through which the education of children with disabilities can be met in fair terms. In the present Century, though India has evidenced a phenomenal vertical expansion in educational facilities and opportunities, children with disabilities are yet to be benefitted specifically that are focussing towards their growth, development and achievement. Inclusive education is a wide spread approach that focuses upon educating the children with disabilities with the regular ones within the same roof. This approach aims to cater to the unique needs of all children irrespective of disabilities and those subjected to marginalization and exclusions. It is the only flexible education stream where all children learn together irrespective of their diversified needs with access to common pre-school provisions, schools and community educational setting with an appropriate network of support services. The present paper aims to highlight the challenges and benefits of Inclusive Education in the Indian context.
\end{abstract}

\section{INTRODUCTION}

A BOUT $10 \%$ of the world's population lives with a disability, and $80 \%$ of these people with disabilities live in developing countries. There exists myriad of differences in facilitating services for persons with disabilities between developed and developing countries. One of these services is education. After the inception of UN Convention on Persons with Disabilities, a broad awareness about different models of special education among the International Community prevailed. Though three fundamental models such as Integrated, segregated and Inclusive education for persons with disabilities have been differentiated by national and international agencies, there is a uniform support for the inclusive education particularly by various agencies, government and non-government organizations and human right activists as it is understood to meet the needs of persons with all levels of abilities.

The Government of India has framed number of policies focussing upon special education after independence since 1947. The Government of India has made meticulous attempts to create policies that are favourable for persons with disabilities but their efforts not resulted in successful implementation of inclusive education system nor have they attained the goal of "education for all" across the country. To

Dr.R. Sree Priya, Assistant Professor, Education, National Institute for Visually Handicapped-Regional Centre, Chennai. E-mail: Vijusreepriya@rediffmail.com

DOI: 10.9756/BIJIEMS.7523 inculcate a sound Inclusive Education system in India, the Government of India need to focus its attention towards bridging the gaps present in the current education system.

\section{INCLUSIVE EDUCATION}

The concept of Inclusive education is loaded with positive terms-full participation, involvement, support, tolerance, individualized instructional approach in group environment, security, assurance, friendship, teamwork, problem-solving, integration, acceptance, recognition, localization, resource mobilization, humane, access to all, success for all, barrierfree and alike. All these must operate in a harmonious environment in the regular class room settings. Thus inclusive education presupposes a unique culture of inclusion.

In inclusive education, all children irrespective of their varied ability levels are admitted in the mainstream schools with least restrictive environment and they are considered as children first and then they are taught equally. The teachers adjust their teaching strategies and curriculum so that the children can benefit to the optimum. This helps to ward off wastage of resources and shattering of hopes, giving space for universal teaching-learning approach.

From certain study reviews it is found that the rate of dropouts and grade repetitions is comparatively less and can visualise upgrade in the levels of achievement in inclusive education system than those systems that are not inclusive in nature. People and personnel who trust in inclusion also trust that the system of education itself is a barrier for child's learning and every child has the potential to learn. It is also evident that the terms such as integration, inclusion and segregation are used alternatively the educational publications and government documents in India. This could stem from a variety of reasons, although a lack of education on the original meanings connected to the words seems to be the most logical explanation.

\section{PRINCIPLES OF INCLUSIVE EDUCATION}

Four fundamental principles which governs Inclusive education are

- All Children should have access to inclusion in the provisions of the mainstream education programs and systems

- Mainstream provision should offer the full range of support and specialized services necessary to give all children their full entitlement to a board and balanced education.

- $\quad$ Parents of children with special education need should be able to choose a mainstream school for their child on the same basis as parents of children without special needs. 
- There should be council for disabled recognizing the rights of all children to education to be achieved progressively and on the basis of equal opportunity and to facilitate the child's active participation in community.

\section{BENEFITS OF INCLUSIVE EdUCATION}

An Inclusive Education provides a foundation for the disabled children in ways that are not possible in special education schools and classes. It tries to bring desired educational opportunities in the vicinity of the disabled children rather than expecting from them to move and try for themselves to avail the opportunities. As it follows the principle of inclusion, the neighborhood general education system is the first placement for any disabled child. Children with all shades of exceptionalities and normality's get opportunity to participate in shared educational experiences. It also facilitated educational experiences with the peers of same age group.

It seeks for all round development of the child in terms of academic, physical social, emotional and vocational educational programmes of the schools. It makes the children with disabilities learn the art of living and get adjusted to real life situations as independently as possible by erasing their feeling of insufficiency or limitedness, or of being different and disabled. It provides an opportunity for the children with diverse needs to participate without discrimination and an opportunity to get integrated in the mainstream schools

\section{Effective Change in the System}

The Inclusive schools accept the responsibility for children's learning by making their systems and methodologies more relevant and responsive to the children's need. It facilitates accessible learning environment that includes mobility and transport issues, the physical accessibility of buildings, attitudes, teaching methods, the language of instruction, the relationship between teachers and children. All the children have a chance to learn and benefit from education, and their achievements can be recognized.

\section{Conducive Learning Environment}

Apart from barrier free features of the school buildings, a conducive learning environment can be created and adapted in the inclusive school settings for all children with different shades of needs. The teacher accepts that the children learn at different level and rates and so plans lessons with diversity and difference in mind; plans activities according to the learning that taking place; cooperates with families and communities for ensured optimized learning to the better possible extent. Teachers can help make the classroom more inclusive by using active, child-centered methods and those methods can

- Encourage all children to play and learn together and share responsibilities.

- Decrease the influences of learning difficulties encountered by children with disabilities.

- Efforts to eliminate the progress of further complications in education.
- Cater to the behavior problems of the children with disabilities/diverse needs.

- Incorporate the skills needed for everyday life into the curriculum.

- Relate what is learnt at school to daily life and home situations.

- Adaptation and application of different methods and pace of teaching to sustain the span of attention and to enable them learn at their own pace.

- Facilitate consistent breaks during learning to ease the difficulties faced by children with severe disabilities.

- To attend to the demands of diversities of children's need with ease.

The settings of the inclusive schools need to access regular intervals of breaks to comfort children with multiple disabilities and with chronic medical conditions. It enables them to maintain concentration and to preserve and means they have an increased chance of benefitting equally from the teaching.

Good management of school is essential when education changes are introduced. The education managers in the inclusive school settings may ensure that teachers are not overloaded, allocates time for teachers to observe each other and promotes multi-sectored collaboration.

\section{Types of Services}

The following are the types of the services rendered in Inclusive Education. The action initiatives and work structure of each service are as follows:

\section{a. Essential Services}

- Planning Instructional Strategies.

- Adequate teaching and maintaining Discipline.

- Maintaining record of curricular and plus curricular activities.

- Facilitating child-to-child learning.

- Consultation with special teachers.

- Conducting examinations and evaluation.

- Interaction with parents.

b. Supportive Services

- Identifying children with disability in the community.

- Teaching Specific Skills.

- Assisting general classroom teacher.

- Arranging for assessment.

- Arranging learning materials, aids and appliances.

- Monitoring the progress of the child through classroom.

\section{c. Peripheral Services}

- Issuing medical reports.

- Providing social benefits.

- Arranging sponsorship to educational activities.

- Counseling to parents and community.

\section{Effective Community Participation}

Establishing a link between schools, families and communities is crucial aspect of inclusion. This link enables to utilize the locally available resources thereby providing an 
opportunity for continued community participation. The long term goal is to promote inclusion in the society as a whole. Also parents may be needed to be helped to organize themselves as a group and to challenge exclusionary practices in the education. Whenever possible, parents of children with disability should be supported to work in partnership with Organizations of persons with disabilities and other community-based groups in advocating for the rights of the children with disabilities.

\section{CHALLENGES AND THE WAY FORWARD}

The major challenges facing the development of Inclusive education systems at all levels are related to the following:

- Regardless of implementation of number of policies in favour of inclusive education, every nation struggles to contrivance and manage a suitable education system that accommodates the requirements of diversity. Experience from many countries show that the development of inclusion policies should be based on a consensus of a philosophy of inclusion. It should be linked to a broader developments, such as a reform of education system, a reform of the status of disabled persons or more general democratic changes.

- Research indicates that the attitudes of the teachers, peers, groups and parents themselves are the barriers to an effective inclusive education (Biswas, 2003).

- Limitations and constraints of many regular schools and lack of preparation of teachers are also considered to be as a barrier for inclusive schools.

- Curricula are not flexible enough to accommodate the diversity of learning styles and pace, as well as to provide possibilities for social and emotional development.

- Support services are necessary to ensure that all learners can learn according to their potential. Instead of focusing on individuals, support should be given to teachers, learners and their families. As support services are expensive, most of the countries have opted to work in collaboration with other sectors, such as health and social.

- Authoritarian control of national/state curriculum features hinders inclusive approach.

- Closed door practise of regular schools for community involvement in decision making hinders the developmental aspect of inclusive schools.

- Building preschools and preparing climate for teacher development at the early intervention level is ill equipped.

- Lack of essential infrastructure facilities in Indian schools such as to meet diverse needs of children with disabilities, disabled friendly transportation are considered to be a major challenge than that of prevailing negative attitudes and social disposition towards disability.

- Lack of awareness of legislation, policies and funding sources and utility pertaining to inclusion among parents, public and school personnel.
- It is visualized as a panacea for all as the inclusive school setting and practices are not guided by any prescriptive model to follow.

- Much organizations concentrates on engaging and training professionals in concerned fields alone a lot.

- The teacher education program curriculum requires revision to favour the concept of inclusion and to upgrade the skills of teacher educators with perspectives to disability. This might involve improving the teaching practices, developing collaborative working and teaching methods, refining teacher's roles, etc.

- Developing countries should develop structures or procedures to facilitate multi-sectoral collaboration to meet the diversified needs globally.

\section{CONCLUSION}

Inclusive education is not only the alternative measures for children with special needs for want of separate special schools for these children but it is a scientific well thought strategy for their overall development; of course it is cost effective and doubly suitable for a developing country like India. Even the Inclusive schools that are in functional status lack facilities to facilitate teaching and learning methods those are innately inclusive in nature. Capability of teachers required to deal children with special needs along with regular children also appear to be poor reflecting the poor quality of training for Inclusive education. Despite of errands and hardships, it is highly relieved with the fact that Government of India has recognized the importance of Inclusive education and had begun to address the diverse needs of children with diverse needs with a march towards universal approach.

\section{REFERENCES}

[1] A. Armstrong, D. Armstrong, C. Lynch and S. Severin, "Special and inclusive education in the Eastern Caribbean: policy, practice and provision”, International Journal of Inclusive Education, Vol. 9, No. 1, Pp. 71-87, 2005.

[2] A. Balu and P. Rajkumar, "AChallenge of Inclusive Education in India”, http://www.worldwidejournals.com/paripex/file.php?val=November_20 15_1447850334_09.pdf

[3] P.C. Biswas, "Random Thoughts on Inclusive Education”, City Book House, 2006.

[4] G. Chatterjee, "The global movement for inclusive education", http://www.indiatogether.org/2003/apr/edu-inclusive.htm

[5] V. Myreddi and J. Narayan, "Preparation of special education teachers: Present status and future trends”, Asia Pacific Disability Rehabilitation Journal, Vol. 10, No. 1, Pp. 1-8, 2000.

[6] "Problems and Prospects of Inclusive Education in India", https://www.researchgate.net/publication/273456327_PROBLEMS_AN D_PROSPECTS_OF_INCLUSIVE_EDUCATION_IN_INDIA.

[7] 'Status of Disability in India', published by RCI, 2000. 